\title{
In Focus
Spotlight on the May 21 issue
}

\author{
Robert A. Gross, MD, PhD, FAAN \\ Editor-in-Chief, Neurology ${ }^{\circledR}$
}

\section{MRI findings and stroke risk in TIA patients with different symptom durations}

This study investigated the association between MRI findings and stroke risk in 3,724 patients with different transient neurologic symptoms lasting less than 24 hours. In 1,166 there was evidence of an acute infarction, with 88 having a stroke during hospitalization. Stroke risk was higher after tissue-positive events than tissue-negative events.

See p. 1920

From editorialists Coutts \& Cucchiara: "Some of us were taught that extremely brief transient symptoms (e.g., less than 30 seconds) are benign, but there are few data other than anecdotal experience to support this. More detailed studies in the less than 1 hour timeframe will be important to address this issue." See p. 1914

\section{Low-dose propranolol and exercise capacity in postural tachycardia syndrome: A randomized study}

The effect of placebo versus low-dose propranolol (20 mg) on peak oxygen consumption was compared in 11 patients with postural tachycardia syndrome (POTS) and 7 controls. Low-dose, but not high-dose $(80 \mathrm{mg})$, propranolol reduced heart rate and improved exercise capacity in patients with POTS.

See p. 1927

Incidence and prevalence of treated epilepsy among poor health and low-income Americans

The Medicaid population had a high incidence of epilepsy, an order of magnitude greater than the general population, with the majority having another condition prior to epilepsy diagnosis. The Medicaid population carries a disproportionate epilepsy burden and deserves more attention for its health care needs and support services.

See p. 1942

Syncope and orthostatic intolerance increase risk of brain lesions in migraineurs and controls

Two hundred ninety-one migraineurs and 140 controls from the CAMERA (Cerebral Abnormalities in Migraine, an Epidemiologic Risk Analysis) study, free of other neurologic symptoms, underwent brain MRI scan and structured telephone interviews including questions on frequent syncope and orthostatic intolerance. Frequent syncope, orthostatic intolerance, and migraine independently increased the risk of white matter lesions, particularly in women.

See p. 1958

\section{Nonmelanoma skin cancer is associated with reduced Alzheimer} disease risk

The authors followed 1,102 adults with a mean age of 79, assessing them annually, followed by multidisciplinary dementia diagnostic consensus. Cancer status and type were obtained by self-report. Individuals older than age 70 with nonmelanoma skin cancer have a reduced risk of developing Alzheimer disease when compared to individuals without nonmelanoma skin cancer.

See p. 1966

Interrater reliability of the new criteria for behavioral variant frontotemporal dementia

With disease-modifying therapies for neurodegenerative disease on the horizon, accurate diagnosis is critical. This study found that clinicians were in "almost perfect agreement" regarding diagnosis of behavioral variant frontotemporal dementia when using the recently validated International Frontal Temporal Dementia Consortium criteria, providing additional support for their use in research and clinical practice.

See p. 1973

\section{CONTEMPORARY ISSUES}

The coming crisis: Obtaining care for the growing burden of neurodegenerative conditions :

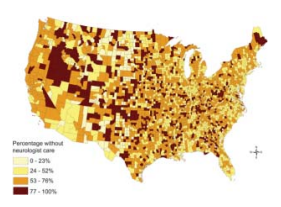

The means and will to provide truly patient-centered care to the millions affected by Alzheimer disease and Parkinson disease is available. What is lacking: Medicare reimbursement policies to support such care. Public engagement will be required to change those policies.

See p. 1989; Editorial, p. 1916

NB: "Background of the Sociedad Neurológica Argentina: Current state and concerns about neurologic education," see p. 1978. To check out other Global Perspectives, point your browser to www.neurology.org. 


\section{Neurology}

Spotlight on the May 21 issue

Robert A. Gross

Neurology 2013;80;1913

DOI 10.1212/WNL.0b013e3182961777

This information is current as of May 20, 2013

\section{Updated Information \&} Services

Permissions \& Licensing

Reprints including high resolution figures, can be found at: http://n.neurology.org/content/80/21/1913.full

Information about reproducing this article in parts (figures,tables) or in its entirety can be found online at:

http://www.neurology.org/about/about_the_journal\#permissions

Information about ordering reprints can be found online:

http://n.neurology.org/subscribers/advertise

Neurology ${ }^{\circledR}$ is the official journal of the American Academy of Neurology. Published continuously since 1951, it is now a weekly with 48 issues per year. Copyright (C 2013 American Academy of Neurology. All rights reserved. Print ISSN: 0028-3878. Online ISSN: 1526-632X.

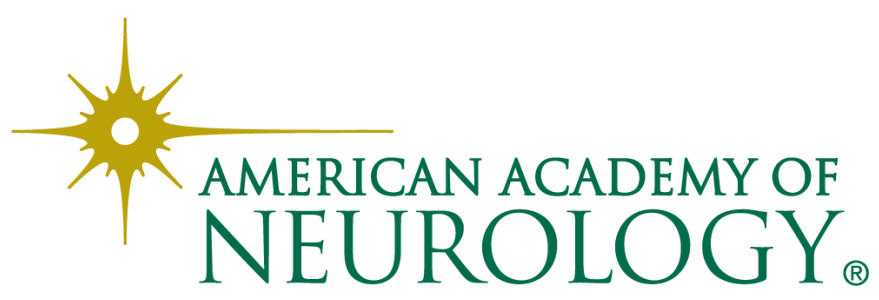

